\title{
THE LOGIC OF TEMPTATION
}

\author{
PAUL M. HUGHES*
}

\section{Introduction}

Temptation is normally thought to be morally dubious, in part because it involves desiring what we think is immoral, imprudent, illegal, unaesthetic, or in some other way wrong or bad. Temptation is also believed to be morally questionable in part because tempting is often a form of manipulation, which we regard as a violation of a person's integrity. ${ }^{1}$ As the Oxford English Dictionary makes clear, temptation has an active and a passive dimension, and temptation as manipulating the wrongful desires of someone illustrates a common form of actively encouraging wrongdoing. Regarding temptation as essentially a matter of manipulating others' wrongful desires, though, misleadingly suggests that all temptations are interpersonal, intentional, and immoral. However, tempting and being tempted may be entirely self-referential, unintentional, and even morally laudatory. These facts suggest that the most important dimension of temptation is not the activity of a tempter but the subjectivity of the person tempted, since without the wrongful desires of the latter temptation of any sort would be impossible. Furthermore, the passive dimension of the standard definition of temptation, the state of being tempted, implicitly raises the question what such a condition involves, and whether it is itself active or passive. If being tempted is a psychological condition in which someone is disposed toward what he believes is wrong or bad, then it is important to identify the beliefs and desires, intentions and motives, knowledge and emotions, or combination of these requisite for being tempted. The extent to which these states are under our control, perhaps even a matter of choice, bears 
on whether we are passive victims of temptation, or active participants, sometimes even co-conspirators, in our own temptations. ${ }^{2}$ So, if we wish to understand temptation as a kind of moral lapse akin to or perhaps even a form of weakness of will, then the perspective of the person tempted should be the main focus of a moral analysis of temptation."

Analyzing the subjectivity of being tempted brings into focus such key questions as whether being tempted is an affective or a cognitive state, or whether it is a combination of the two involving a desire for what we believe is in some sense evil or wrong. Perhaps temptation is even more complex than this, involving in addition a characteristic "feel" such that it is more like an emotion than a desire. Moreover, if temptation is not always interpersonal, involving one person seducing another into imprudent or otherwise wrong behavior, then how is self-tempting different, both psychologically and morally, from interpersonal temptation? Other queries such as what things can tempt, what sorts of beings can be tempted, whether it is possible to be tempted to do good, whether one is always blameworthy for being tempted or for yielding to temptation, and whether temptation ever functions as an excuse for wrongdoing, may admit of clearer resolution by approaching temptation from the perspective of a person tempted rather than from the standpoint of a tempter.

In this paper I explore some of these questions, arguing that although temptation is a relational phenomenon involving a tempter and a person tempted, temptation depends crucially on the beliefs, desires, and emotional attitudes of the person tempted. Moreover, the dependency of temptation on the subjectivity of the person tempted entails that there is no logically necessary tie between temptation and evil. I suggest, furthermore, that holding someone morally responsible for temptation depends on such factors as whether it is interpersonal, intentional, and whether and in what sense a moral agent can be held responsible for her character.

I begin by distinguishing different senses of temptation in order to set out more clearly the core moral meaning of the term. I then offer an account of what is involved in temptation from the standpoint of a person tempted. This phenomenological account sets the stage for clarifying 
how and under what circumstances we may be tempted to do what is morally right or good, and suggests the direction for further research into questions about personal responsibility and temptation.

\section{Two Senses of Temptation}

Temptation admits of two normative senses, a primary meaning which is essentially moral, and a secondary meaning which is non-moral though nevertheless frequently evaluative. The Oxford American Dictionary lists "to arouse a desire in" and "to attract" as this second meaning of the term. ${ }^{+}$This common meaning is invoked in such colloquialisms as that I was tempted to have another cup of coffee. or phone a friend I haven It spoken with in months. These examples suggest that we often use temptation to mean nothing more than "desire" or "desire to do," and thus that temptation is sometimes used in a non-moral way. Though nonmoral, this sense of temptation may nevertheless be normative, since to desire or want to do something often involves possessing a pro-attitude toward the object of desire.

But the central meaning of temptation. according to the Oxford English Dictionary, is "the action of tempting or fact of being tempted, especially to evil." This sense of the term makes clear that both the active and passive aspects of temptation have a special relation to evil. Although this view may be compatible with being tempted to do good, it seems exceedingly odd to suppose, for instance, that someone might be tempted to tell the truth, or care lovingly for her child, or obey the law. And so we need to know more about the relationship between temptation and evil if only to determine whether it is possible to be tempted to do that which is right or good. One recent author goes so far as to assert that both tempting and being tempted are necessarily immoral, implying that the link between temptation and evil is conceptual. ${ }^{6}$ If so, then it is not merely odd but absurd to suppose we might be tempted to do what is right or good. An inquiry into the phenomenology of temptation, including the epistemic requirements for being tempted, will help resolve some of these questions and clarify the relationship between temptation and evil. 


\section{A Phenomenology of Temptation}

A recent account of temptation maintains that to tempt involves intentionally engaging a person's desire for what is in some sense wrong. ${ }^{7}$ This suggests that temptation typically involves a tempter who intentionally stimulates the wrongful desires of someone else, and this is surely a plausible account of the relational structure of many temptations. "Though many temptations involve such manipulation, it is important to note that there can be no tempting if there are no people with wrongful or unruly desires. Consequently, temptation depends essentially on the beliefs, desires, and emotions of those who are tempted. What tempters do when they deliberately tempt is an important factor in interpersonal temptation. However, the role of the subject of temptation is more complex and theoretically richer than an emphasis on the manipulative role of tempters can recognize. This is so because emphasizing how tempting can be manipulative assumes the centrality of the activity and behavioral consequences of tempting rather than the experience of being tempted and the internal struggle this frequently involves. Accordingly, I shall focus primarily on the role of wrongful desires in experiencing temptation, which I will argue is key to a fuller account of the psychological and moral nature of temptation.

Clearly, tempting involves desire, but since not all desire is temptation, they cannot be the same. Moreover, not all desire even for what someone believes is evil (e.g. my wish that my enemy suffer public humiliation) is temptation, for though all desire for evil involves an attraction to it, it does not follow that it involves a motive to cause the evil(my desire that my enemy be humiliated in public need not motivate me to cause his humiliation, or to do anything at all). In short, desiring does not entail being motivated to do anything:" "Doing something" should be construed broadly, for one may be tempted to act, think, or even feel. I take it that one may be tempted, for instance, to wallow in self pity, or begrudge another her just reward, and not only to behave overtly in some way toward another person or thing. Moreover, that temptation involves a motive does not imply that one acts on that motive, for other, even incompatible, motives (e.g. self interest), may be stronger, and thus be, as Frankfurt would say, one's effective desire. ${ }^{10}$ 


\section{THE LOGIC OF TEMPTATION}

Though it is not entirely clear what sorts of things can tempt, it seems plausible to suppose that in addition to standard cases of interpersonal tempting (i.e. one or more persons tempting another or others) people may tempt themselves, or be tempted by inanimate objects or animals. Obviously, inanimate things and animals do not make offers, nor do they scheme or otherwise intend to take advantage of a person's unruly desires, and so being tempted by them does not involve manipulation. " Still, many people recognize in such objects or beings opportunities that arouse their wrongful desires. In this way things and animals may tempt.

It is important however to recognize that animals and inanimate objects like jewels only tempt passively, and are not tempters in anything like the sense in which people may be. Though it is reasonable to say of a person tempted to steal diamonds that she is tantalized by the glitzy objects of her desire, it would be wildly implausible to say that such objects exploit or otherwise manipulate that person's weakness for illgotten gain. Consequently, though objects, animals, and opportunities may tempt passively, only persons can tempt actively. ${ }^{12}$

Thus, being tempted involves a desire for what one believes is in some sense wrong or bad, along with a motive to fulfill that desire. It is also worth noting that being tempted has a characteristic feel not entirely expressed by the idea that one desires what one thinks is wrong or bad, even when such desires involve pro-attitudes. In that moment of moral vacillation constitutive of temptation, one is simultaneously disposed toward and opposed to evil rather than indifferent to it, irrespective of how that moment is resolved (i.e. whether one yields to or resists the temptation). Like all ambivalence, temptation is typically an uncomfortable state, but it is not the case that all uncomfortable states are temptations. For example, we sometimes desire what we can't have (e.g. another person's spouse) and the fact that we want what isn't available, or what we shouldn't want, is distressing. Sometimes, too, we want what we can (or even already) have, yet the desire is so intense (e.g. blinding infatuation for one's lover) as to make us miserable. These sorts of uncomfortable states involve desires, and they sometimes involve conflicting emotions, yet they need not function as motives, and are thus not temptations. Put differently, to be tempted cannot be just any dissonant 


\section{PAUL M. HUGHES}

subjective state in which our desires are at odds with our feelings or beliefs about what we should have or do, because being tempted is desiring to do something believed to be evil, and is thus necessarily a motive.

Temptation, then, is an ambivalent state, and is in part pleasurable. ${ }^{13}$ This positive affective dimension seems to be an essential element of the experience of temptation. Peter Abelard is explicit about this in his account of the role of temptation in sin. Abelard contends that

If we already know that such a deed (i.e. a wrongful act) will be pleasant, our imagination is held by anticipatory delight and we are tempted thereby in thought. So long as we give consent to such a delight we sin. Lastly we pass to the third stage, and actually commit the $\sin .14$

Temptation is here conceived as involving anticipatory delight in doing something wrong. Anticipatory delight is an emotion, one which in this case has as its intentional object the expected pleasure of engaging in a wrongful act. This is not the same as sin, according to Abelard, for that latter condition requires something more than mere anticipatory delight in the prospect of pleasurable wrongdoing, namely, consent. To sin is to embrace or endorse one's anticipatory delight in pleasurable wrongdoing. Consenting is thus in the case of sin a second-order desire or attitude about a first-order desire; it is, in other words, an attitude that ratifies the lower-order desire to do what is wrong. ${ }^{15}$ By contrast, to be tempted is to be in a complex state of character partly defined by welcoming what we believe is wrong, but since we may be disgusted or otherwise repulsed by our anticipatory delight about prospective wrongdoing, the second-order attitude of consent is not a requirement of temptation. A second-order emotional attitude of some sort typically accompanies temptation in its standard moral sense, and the list of possible candidates is a long one. Such evaluative attitudes will presumably be negative, including such emotions as shame, regret, fear, disappointment, horror, guilt, confusion, anger, dread, and self-loathing. Perhaps such positive attitudes as amusement, glee, or wonder sometimes accompany temptation as well, though these would not seem to be 


\section{THE LOGIC OF TEMPTATION}

constitutive elements of temptation. ${ }^{16}$ So, embracing anticipatory delight is not a requirement of temptation, though possessing some critical emotional attitude toward that delight usually is. ${ }^{17}$

It is important to stress the difference between the first-order desire/ emotion of temptation (i.e. anticipatory delight) and the second-order emotional attitude (e.g. shame) that is typical of temptation in its full moral sense. To desire something is at least sometimes to be attracted to or have a pro-attitude toward it. But not all pro-attitudes are morally evaluative even if they are valuations in some sense (e.g. a dog craving a bone in some sense values the bone). Anticipatory delight is a necessary first-order constitutive desire/emotion of temptation, and is thus a necessary but not sufficient condition of being tempted. This first-order emotional attitude is different from the second-order critical attitudes of anger, confusion, fear, and attitudinal normative beliefs one or more of which must accompany the first-order desire for temptation in its full moral sense to occur.

A final question about the phenomenology of temptation needs to be addressed before we can determine the precise relationship between temptation and evil, and this has to do with the epistemic conditions of temptation. Specifically, does temptation require knowledge or merely the belief that the object of temptation is evil? Suppose, for the sake of argument, that to be tempted presupposes that we know that what we desire is wrong or bad. On this view, being tempted will depend on our desiring what is in fact wrong. So long, therefore, as we believe truly that what we desire is wrong, we are being tempted. By contrast, if we do not know that what we desire is wrong or bad (e.g. we falsely believe that what we desire is wrong, or have no beliefs at all about the morality of what we desire), then we cannot be tempted. This is so because what we desire either is not wrong at all, or it is not wrong in the way we think it is (though it may be wrong in some other sense). Imagine, for instance, that Jones believes that eating meat on Fridays is a sin. Further suppose, for argument's sake, that she is mistaken about this. Dining out with a friend one Friday night, Jones finds herself craving a steak dinner, which she sincerely believes she should not have. Her friend encourages her to satisfy her craving, arguing that in the "big picture" it can't matter very 


\section{PAUL M. HUGHES}

much whether or not she eats meat on Fridays. On the assumption that being tempted requires knowing that what one desires is in some way wrong this would not be a case of temptation. But this is extremely counterintuitive, for what else could it be but temptation?

Thus, being tempted does not require that we know that what we desire is somehow wrong or bad. Instead, a weaker condition is all that is required, namely, we must believe that what we desire is wrong or bad. ${ }^{18}$ This fills out the preceding phenomenological account of temptation, yielding the view that temptation is a complex psychological state involving desire, belief, motivation, and a characteristic affect. Whether or not temptation occurs thus depends essentially on the psychology of the subject of temptation rather than on the actions of a tempter. Try as one might, nobody can tempt another person unless the psychological pre-conditions of being tempted are present, and these are, except in unusual cases, independent of the actions of a tempter. ${ }^{19}$ Perhaps, though, this last point is overstated since it assumes that because wrongful desires precede temptation they are therefore independent of the actions of tempters. Rather, it may be that our routine temptations are caused by others who arrange environmental stimuli so as to generate our wrongful desires and the opportunities to fulfill them. The extent to which we are in this way intentionally or unintentionally "set up" for temptation raises large and complex questions about how socio-economic realities influence the formation and stimulation of individual and collective desires and beliefs. It is enough to point out here that if to be tempted requires that we know that what we desire is wrong, then we will first need to know how such socio-economic phenomena shape and manipulate individual and collective beliefs and desires. This in turn would enable us to distinguish true from false beliefs. ${ }^{20}$

The epistemology of temptation thus implies that if we believe that an illegal, immoral, or otherwise wrong act is permissible or obligatory, then we cannot be tempted to do it. This does not mean that a would-be tempter cannot attempt to tempt us. Nor does it mean that a would-be tempter cannot do such similar things as cajole, provoke, importune, or compel us to act wrongly, or reward, punish, or threaten us if we fail to do so, and for these modes of influencing us a would-be tempter may be 
held morally accountable. But attempting to tempt, cajoling, provoking, and other modes of influencing are not the same as tempting.

\section{The morality of tempting: A Preliminary (Kantian) Sketch}

I have argued that being tempted is an ambivalent state constituted in part by wanting to do what we believe is wrong. I have also claimed that this state involves a necessary link between temptation and perceived evil, and that although the connection between temptation and perceived evil is logically necessary, it does not follow that there is such a relation between temptation and actual evil. Consequently, it is possible to be tempted to do that which is in reality morally good.

These facts raise the question of the moral status of temptation, with regard both to those who tempt and to those who are tempted. Although I have thus far focussed on the moral psychology of being tempted, since temptation is relational (even in cases of self-tempting), a plausible moral evaluation of temptation will need to be informed by both sides of the relation. Consequently, $\mathrm{I}$ shall in this and the following section discuss the moral status of tempting and of being tempted, alternating between an analysis of each. I begin with some observations on the morality of actively tempting.

At the start of this paper I remarked that deliberately tempting others is morally dubious because it is often a form of manipulation, which is widely regarded as a violation of personal integrity. ${ }^{21}$ This view, along with the fact that it is possible to tempt someone to do what is right or good, implies that it is morally objectionable to tempt someone to do the right thing. But how can this be?

My answer is Kantian in spirit, as is, I suspect, the common intuition that it is immoral to tempt others to do what is wrong. In manipulating another person we treat him as a means to an end, rather than as an end in himself. This is a violation of moral agency because it compromises moral autonomy. Respecting the moral autonomy of others requires that we allow them to make their own moral decisions. What is morally objectionable about tempting someone to do the right thing is the attempt to persuade him to act contrary to his beliefs about what he should do. If successful, such an effort results in his doing the right thing by a tempter's 


\section{PAUL M. HUGHES}

design, a scheme which robs him of the possibility of behaving in a morally worthy manner, if, pace Kant, moral worth requires intending to do what is right. ${ }^{22}$ So, it is at least sometimes wrong to use another as a means to moral goodness.

This evaluation is complicated, though not altered, by the fact that tempting another person to do what is right admits of two versions. On the one hand, a tempter may know that what he is encouraging another person to do is morally (or legally, prudentially, etc.) right though the person tempted believes it is wrong. On the other hand, a tempter may take himself to be urging another person to do something she thinks is wrong, something which the person tempted also believes is wrong, but which is in fact right. ${ }^{23}$ Either option, as far as I can tell, admits of the aforementioned qualified Kantian assessment of the morality of tempting. This is so since in either case a tempter manipulates his victim, thereby compromising the latter's dignity as a moral agent.

With regard to the moral status of the flip side of the relation, that is, the moral status of those who are tempted, the immorality of desiring what we believe is wrong or bad is straightforward. We shouldn't desire or do what we think is wrong. Being tempted to do the right thing is, accordingly, a special case of this more general judgment, and right actions motivated by temptation are right actions done, in a sense, for the wrong reason. Yielding to such temptations also admits of a Kantian negative moral analysis, since doing what we think is wrong cannot be, by definition, acting from duty (i.e. doing what's right because it's right).

Since there are different ways of being tempted to do the right thing, there are different moral evaluations appropriate to them. As noted above, a person might possess false beliefs about the morality of an action and so be tempted to do what is in fact right. If one yielded to such a temptation he would presumably be blameworthy for doing what he believed was wrong, though this judgment might be tempered by the fact that his ignorance was understandable and the temptation very strong. But other temptations to do the right thing are morally worse insofar as they involve a greater degree of intentionality and/or the presence of morally undesirable character traits like selfishness. Just such a case is the object of T.S. Eliot's pronouncement that "the last temptation is the greatest 


\section{THE LOGIC OF TEMPTATION}

treason: to do the right thing for the wrong reason." Eliot tells of an Archbishop who, successful in resisting various worldly offers to stray from his service to God, in the end yields to his selfish desire for a lofty reputation among men. ${ }^{24}$ This example shows how self interest often figures prominently in temptation, and illustrates too that people sometimes invoke morality itself (or religious ideals) to rationalize yielding to temptation. ${ }^{25}$ Temptations that involve taking the moral high road are, in fact, as mundane as they are despicable. The phenomenon of malicious truth-telling is a clear case. A busybody with a grudge against his neighbor may reveal an unpleasant and professionally damaging truth about that neighbor to the media, invoking as justification the rationale that publicizing the truth is always morally permissible. The idea that the truth is its own justification coincides with the widespread conviction that honesty is a moral virtue. Although recognized in law as a defense against libel and slander, this intuition is denied in the doctrine of "malicious truth." The core idea of the doctrine of malicious truth is that publicizing damaging truths that serve no public interest, or doing so from unworthy motives (e.g. revenge) is beyond the protection of the law. ${ }^{26}$ The "truth" is thus not always its own justification. ${ }^{27}$ Similar intuitions are relevant in determining the morality of publicizing damaging truths, and just as we can distinguish malicious (and unjustified) truths from justified yet damaging ones in law, so too we can distinguish immoral malicious truths from damaging truths that are morally permissible or even obligatory to make public. If, for example, one comes across information that one's employer is extorting sexual favors from a colleague, or embezzling funds, or taking bribes from a competitor, then one arguably has a moral duty to publicize that information, particularly if doing so is the only or the best way to combat the injustice. But if one's motive for publicizing such information is retaliation for having been passed over for promotion, and not because one has a duty to publicize it, then we have the sort of case in which a person yields to a temptation to do what is right or good in a way that renders him more vile than he would be if he yielded to a similar temptation but was blamelessly mistaken about what was, in fact, morally right. 
Thus, what makes yielding to some temptations to do the right thing worse than others is the role of deliberation and morally undesirable character traits or motivations in being tempted an/or in yielding to temptation. In other words, what makes some temptations to do the right thing worse than others is that consciousness and intentionality render a person more complicit in temptation than is the case with those temptations wherein ignorance of what is right and the strength of our desires combine to motivate action.

\section{The Morality of Temptation: Further Considerations}

There is, of course, more to the morality of being tempted than a Kantian-inspired analysis reveals, and in fact such a view is arguably misguided, for if an action is morally right, then it cannot be wrong to perform it, notwithstanding the fact that the action may cause great hardship. Moreover, even though people sometimes do the right thing for immoral reasons, such as to take revenge on an enemy, it would be a mistake to insist that doing the right thing for the wrong reason means that one has not done the right thing. Instead, we can parse the morality of actions into overt physical behaviors, on the one hand, and internal mental and other characterological phenomena, on the other. In so doing we recognize, of course, that mental states (such as desires, motives, intentions, and emotions) and character traits, dispositions, proclivities, and temperament influence our evaluation of human actions, but that there is more to the morality of behavior than these. Indeed, the divergence between motivation and deed is what gives Eliot's "greatest treason" temptation its force, and allows us to recognize that yielding to a temptation to perform a right action from ignoble motives such as revenge, contempt, or malice is, far from being impossibie, not even especially rare.

It might also be objected that this Kantian account of the immorality of being tempted to do the right thing assumes what needs to be demonstrated, since the description of malicious-truth telling and similar cases ignores the fact that the persons tempted are doing something they believe is morally objectionable, and thus that they do not regard themselves as doing the right thing. The fact that they see themselves as 


\section{THE LOGIC OF TEMPTATION}

doing something wrong does, of course, help explain how they can be tempted, since temptation requires the belief that what one wants to do is somehow wrong. But a more plausible description of malicious truthtelling and similar cases of doing the right thing for the wrong reason is that those who do such things are tempted to do what they think is wrong (e.g. work off a grudge, take revenge on an enemy, etc.), not right. It is, therefore, at least misleading to say they are tempted to do the right thing.

This objection is correct insofar as a full description of the goings on in malicious truth-telling and similar cases must reveal that the person tempted takes himself to be doing something inappropriate; otherwise there are no grounds for saying he is tempted. Still, if it is legally or morally permissible or even obligatory to reveal damaging information, the motives and beliefs of the person doing so do not change that fact, and it is right to publicize such information. That one does the right thing by yielding to temptation is what allows us to describe such a case as doing the right thing for the wrong reason. ${ }^{28}$

The matter is even more complex, for not all temptations are intentional, and this fact bears on the moral status of those who tempt and those who are tempted. Because one may intentionally or unintentionally stimulate another's wrongful desires, there are two main cases of interpersonal temptation. Deliberately stimulating others' wrongful desires is, as I have argued, a form of manipulation or exploitation. By contrast, unintentionally stimulating others' unruly desires may be regarded as a kind of "innocent" temptation. ${ }^{29}$ If this distinction between manipulative and innocent temptation is sound, then temptation involving manipulation is a necessary though insufficient condition for the moral blameworthiness of a tempter, even when she tempts someone to do what is actually morally right or good. The concept of temptation thus does not entail immorality on the part either of someone who (deliberately or innocently) tempts, or of the person tempted, even when tempting involves engaging a person's desire for what he regards as wrong. So, tempting and being tempted are not necessarily immoral.

Still, the link between evil and temptation is a strong and not easily 
defeasible one, for persons' normative beliefs do not occur in a social vacuum. Rather, personal beliefs about morality, religion, aesthetics, etiquette, law, and politics are normally connected to more widely held community beliefs, beliefs the internalization of which partly define us as the sort of moral agents we are. This connection means that being tempted usually involves desiring what one, and one's society, believes is inappropriate in one way or another, and ordinary cases of temptation, for example, being tempted to cheat on one's lover, or underpay taxes, or eavesdrop on private conversations, show this. As I suggested earlier, temptation is an essentially relational phenomenon, not a passion play that occurs exclusively in one's own private mental theater. With no relation to a social context that provides the setting in which temptations occur and derive their moral meaning, nobody could ever tempt or be tempted.

This fact about the genesis and social connectedness of personal beliefs should serve as a corrective to the possibly misleading impression conveyed in the earlier analysis of the role of individual beliefs in the phenomenology of temptation. Tempting and being tempted are ordinarily immoral, for they involve the real or at least perceived attempt to transgress social norms central to our identity as moral agents. Thus, the logical possibility that one may be tempted to do what is morally good does nothing to alter the fact that temptation and moral evil are for practical purposes closely linked. This fact, though, should be tempered by the possibility noted above that the socio-economic context in which we are shaped and our relations with others are structured may be complicit in our temptations to a greater degree than we are aware. Thus, the link between temptation and genuine evil may remain obscure.

Clearly, a person may be tempted to do what is in fact right by the circuitous route of having one's false beliefs about the impropriety of an act exploited by a tempter. One may also be tempted to do what is right by being motivated by or yielding to morally despicable desires (e.g. revenge) to do the right thing. But these possibilities do not shed light on whether one may be tempted to do what one believes is right. The truth conditions for the following statements suggest a crucial difference between temptation and perceived evil, on the one hand, and temptation 


\section{THE LOGIC OF TEMPTATION}

and perceived goodness, on the other; a difference which argues against the possibility of being tempted to do that which one believes is right:

(A) I was tempted to steal the money left unguarded on the desk.

(B) I was tempted to donate my lottery winnings to charity.

Note that (B) seems to require more information to articulate its full sense, while (A) does not. This of course may be because people do not typically donate prize winnings to charity, but that fact actually supports the standard sense of temptation as involving wrongdoing, rather than its involving morally right, obligatory, or supererogatory behavior. So, we expect someone who utters (B) to complete the thought by saying something like "rather than spend it on my wife," or "rather than spend it on the new car I've been promising myself," and the like. But (A) does not require this sort of "rather than" clause for its completion; it would be linguistically perverse for someone to say, "I was tempted to steal the money left unguarded on the desk, rather than leave it alone," or, "rather than leave it for its rightful owner." This suggests that the notion that one may be tempted to do that which one believes is right does not make sense on its own, that some further explanation is necessary to make it plausible. ${ }^{30} \mathrm{By}$ contrast, the notion that one may be tempted to do wrong is a complete thought. Consequently, it does not seem possible to be tempted to do what one thinks is morally right or good.

The logic of temptation is such that, finally, if the distinction between exploitive and innocent temptation is sound, it follows that innocent temptation does not reflect immorally on a tempter, for he does not deliberately engage the unruly desires of another person. ${ }^{31}$ This still leaves unresolved the full moral status of the person tempted, which status is connected, in part, to the origins and persistence of his wrongful desires. To shed light on this topic requires clarifying key issues about the formation of, and responsibility for, personal character, which is beyond the scope of this essay. Perhaps it is safe to say at least that if you are tempted to do what is morally wrong, then your desire for wrongdoing is prima facie evidence of a morally flawed character. The nature and scope of such a flaw is itself a complex matter, since we would need to 


\section{PAUL M. HUGHES}

determine the full moral status of being tempted. And this would involve determining whether our susceptibility to temptation is an inveterate and ineliminable moral imperfection, or something that is correctable. We would also need to determine the moral status of yielding to temptation (is this indicative of a certain sort of general powerlessness or inability to control ourselves, or, instead, is it evidence only of occasional lapses of willpower?). These issues suggest that even if we are the authors of our character, there are further questions about how temptations and our reactions to them reflect on us, and whether in the end we are blameworthy for having wrongful desires. And, even if we are not the authors of our character, manipulative and innocent temptations may yet reflect negatively on us if only in the sense that we are morally worse persons than we would otherwise be if we did not possess wrongful desires. ${ }^{32}$ The resolution of these issues is a topic for another paper.

\section{Conclusion}

In this essay I have attempted to shed some light on temptation, arguing that there are two main senses of the concept. One sense of temptation is used casually to refer to garden variety desires and attractions, and another, the main moral sense, connotes a desire for what one thinks is in some way wrong. I have claimed, furthermore, that analyzing temptation from the standpoint of a tempter, and taking deliberate interpersonal temptations as paradigmatic, ultimately misconstrues temptation by under-appreciating the essential role of the subject of temptation. Without an adequate phenomenology of what it is to be tempted, temptation as a relation between a tempter and a person tempted cannot be understood. The phenomenology of temptation reveals, moreover, the epistemic requirement that a person tempted need only believe that what she desires is somehow inappropriate, and thus that the link between temptation and objective evil is a contingent, not a logically necessary, one. I have also suggested that the assignment of moral blame when persons are tempting or are tempted depends in part on whether a tempter intentionally or unintentionally tempts. It depends too on what a tempter takes himself to be doing when he deliberately tempts someone else and on the role of choice and control in the formation 


\section{THE LOGIC OF TEMPTATION}

and perseverance of our wrongful desires. This last factor depends, in turn, on issues related to the construction of moral character.

\section{UNIVERSITY OF MICHIGAN-DEARBORN DEARBORN, MICHIGAN 48128}

\section{NOTES}

* I thank Robert Holland and H. Skott Brill for helpful comments on an earlier version of this paper.

1 The Oxford English Dictionary defines temptation as "The action of tempting or fact of being tempted, esp. to evil" (Second edition, 1989, Volume XVII, p.759). The Oxford American Dictionary defines the primary sense of "tempt" as "to persuade or try to persuade (especially into doing something wrong or unwise) by the prospect of pleasure or advantage." (New York, Avon Books, 1980, p.706).

2 Questions about responsibility for character arise naturally in this context, and some philosophers have argued that a person may be blameworthy for weakness of will or other moral infirmities if such defects are a consequence of blameworthy failures to develop relevant character traits. See, for example, Gary Watson, "Skepticism about weakness of will," (The Philosophical Review, Vol.86, 1977, pp.316-339).

3 For a fuller account of the active dimension of temptation see my "Temptation and the manipulation of desire." Journal of Value Inquiry 33: 371-379, 1999.

$4 \quad$ Oxford American Dictionary, (Oxford University Press, 1980), p.948.

5 Op.Cit.

6 J.P.Day, "Temptation," American Philosophical Quarterly, 30.2, (April, 1993), pp.175-183.

7 Day, op.cit.

8 Hereafter I use the phrases "wrongful desires" and "unruly desires" as shorthand for "desiring what is in some sense wrong." As will become clear, I subjectivize this as "desiring what one believes is in some sense wrong" to accord with my view that temptation is an essentially subjective phenomenon.

9 See Harry Frankfurt, "Freedom of the will and the concept of a person." (Journal of Philosophy, Volume LXVIII, No.1, January, 1971, pp.5-20) for an account of how various desires may coexist without any one of them 
being a person's "effective desire" (i.e. his "will", or what I am here calling his "motivation").

10 I should perhaps make clear here that I regard motives as intermediate between Frankfurt's desires and his notion of an effective desire. A person may possess desires which exert no behavioral influence at the moment (and perhaps never in their life), or desires that compete as candidates for effective desires that in fact motivate present behavior (i.e. effective desires). This trio of desire-types clarifies the nature of temptation by making clear its motivational aspect while yet allowing for the reality that people sometimes resist the pull of temptation.

11 On the aforementioned manipulation theory of temptation, all intentional temptations are thought to be immoral, and so are typically masked as ordinary "offers." See Day, op.cit, p. 176.

12 Persons, too, may tempt passively, and although objects, animals, and opportunities do not make offers, they can be part of an offer by being used to manipulate persons' unruly desires, and in this way may be involved in active temptations.

13 The Oxford English Dictionary alludes to this in defining "tempt" as "to persuade or try to persuade (especially into doing something wrong or unwise) by the prospect of pleasure or advantage." Emphasis added. My description of temptation as an ambivalent state is an effort to render intelligible the emotional attitudes that this definition connotes. When tempted one is usually aware of an action, object, or event one thinks it would be somehow wrong to perform, possess, or experience, and yet which one welcomes.

14 Peter Abelard, "Desire and Sin," reprinted in Christina Hoff Sommers, Vice and Virtue in Everyday Life, third edition (Harcourt, Brace, Jovanovich, 1993), p.360. See also Peter Abelard, Ethical Writings, translated by Paul Vincent Spade (Hackett Publishing, 1995), pp.14-16, passim.

15 To sin therefore involves a second-order desire that renders a first-order desire effective. That is, one sins when one wills to do wrong, and this involves choosing to make the first-order desire of anticipatory delight in wrongdoing one's motive to action. Note that on Frankfurt's view only persons have this ability to enact second-order desires. I suggest this ability is a mark not only of personhood, but of moral agency as well. This means that the present account of temptation applies only to beings capable of second-order desires, which are inherently evaluative. This is as it should be, since the temptations of infants, dogs, and other non-moral agents are properly explicable only as first-order desires (i.e. the desires of non-moral agents).

16 I say such second-order emotional attitudes would presumably be negative 


\section{THE LOGIC OF TEMPTATION}

since temptation is a state of ambivalence requiring that its constitutive positive attitude (anticipatory delight) be opposed by a negative secondorder attitude of the sorts listed. The presence of other, even positive, emotional attitudes in the experience of temptation is not ruled out by this analysis, though such emotions will not be necessary elements of temptation. Moreover, I contrast Abelard's notion of "consent" as an attitude with emotional attitudes because temptation $i s$ an ambivalent state, whereas sinning may not be. One may wholeheartedly sin, experiencing no conflicting emotions or attitudes about it, but to be tempted is to be divided.

17 Perhaps the idea that a second-order critical emotional attitude toward anticipatory delight typically accompanies temptation over-intellectualizes the phenomenology of many temptations. A child of twelve may have no second-order emotional attitude about the anticipatory delight of his temptation to steal candy, yet possess a critical attitude of another sort, namely, that stealing is wrong, his parents would be furious if he did it and they found out, etc. The object of these sorts of critical beliefs would be the act of stealing, not the anticipatory delight of the temptation to steal. This means that the internal conflict necessary for temptation need not be between anticipatory delight and another higher order emotional attitude, but may instead be constituted by a conflict between a normative belief about the wrongness of yielding to temptation and the first order emotional attitude of anticipatory delight. This preserves the ambivalence required of temptation, as long as the normative beliefs in question are "attitudinal" as such beliefs are construed by philosophers such as Thomas Nagel and R.M. Hare.

in It might be objected that this weaker "belief" requirement of temptation is still too strong, since it appears to rule out the possibility of tempting young children who neither know nor believe that what they desire is wrong. There is, however, a distinction between tempting and other modes of influencing persons, and cases involving young children seem to me more akin to luring, enticing, or simply offering, none of which require either knowledge or the belief that what we desire is wrong. Moreover, insisting on the belief requirement in cases involving very young children is a mistake, for they are not yet moral agents in the full sense of that term and do not have the requisite second-order attitudes to experience temptation morally.

19 They are independent of the actions of a tempter in the minimal sense, at least, in which in deliberate interpersonal temptation for someone to be tempted he must already possess wrongful desires and be in a weakened state of resistance with respect to them. What the tempter typically adds to this mix is a desirable illicit object, often supplemented by goading, 


\section{PAUL M. HUGHES}

persuasion, or deceit. These sorts of activities no doubt often contribute to the weakening of another person's will, and perhaps most cases of (intentional or unintentional) interpersonal temptation involve this. Of course, truly insidious tempters might implant the wrongful desires they then manipulate. This latter possibility is not far removed from the psychological principle known as priming, the activating of concepts in our minds that affect how we behave. Though this happens naturally in response to environmental stimuli, it can be deliberately effected for purposes of manipulation, as when advertisers link sales messages to images unrelated to their products in an effort to influence consumer behavior, or when police entrap innocent citizens into committing crimes. For an account of priming and its use in manipulative messages see John A. Bargh, The Automaticity of Everyday Life (Eribaum, 1997).

20 This is a potentially enormous undertaking since it would involve, at the very least, a psychological theory that would allow us to distinguish authentic from inauthentic desires, as well as a moral epistemology that enabled us to distinguish true from false moral beliefs.

21 The interesting, though puzzling, case of tempting God escapes this analysis. In a symposium on the nature of religious assertions (reprinted in God, Timothy Robinson, ed., Hackett Publishing, 1996, pp.96-105), Basil Mitchell invokes this idea in the context of contrasting the Christian conviction that God exists with the agnostic idea that the claim "God exists" is a "provisional hypothesis to be discarded if experience tells against (it)." The Christian, Mitchell tells us, "is precluded by his faith" from adopting the agnostic stance, for "Thou shalt not tempt the Lord thy God." Tempt the Lord to do what? If God is wholly good, then isn't temptation impossible for Him? It might yet be wrong to try to tempt God, and morally wrong to do so. But this would be an impossible attempt, since it is impossible for God to be tempted in view of the fact that His omnibenevolence is incompatible with His desiring evil of any kind. Of course, the usual interpretation of tempting God relates to "testing" Him. People sometimes predicate their faith in God on His not allowing certain evils to transpire in their lives, in effect conveying the message that their faith is contingent upon how God behaves. This sense of tempting God clearly does not assume that God could desire evil.

22 This Kantian assessment should be qualified, since the broader moral schemes in which individual temptations are embedded may justify tempting others (even to do that which is morally right) on the grounds that doing so is, all things considered, the morally best course of action. For example, Oskar Schindler's bribing of German soldiers to allow Jews to escape Nazi death 


\section{THE LOGIC OF TEMPTATION}

camps by routing them to Schindler's factories seems to be a morally laudatory instance of tempting people to do the right thing.

Both possibilities reflect the fact that the link between temptation and evil is contingent, since encouraging someone to do what you falsely believe is wrong, and falsely believing that what you desire is evil, are subjective perceptions that need not correspond to reality. Moreover, both possibilities require that the person tempted must believe that what she wants to do is wrong, otherwise temptation cannot occur.

24 The "last" temptation refers to the fourth in a series of temptations of Thomas Beckett, Archbishop of Canterbury, in Eliot's Murder in the Cathedral. Though the first three tempters try to seduce Beckett with mundane rewards such as political power and material gain, the fourth plays on Beckett's pride in renouncing such worldly goods in the name of serving God. The last temptation is thus an effort to lure Beckett into refusing earthly enticements in order to achieve a lasting reputation as a steadfast servant of God. But this is to use God as a means to one's own glory, rather than to use oneself to glorify God. Hence, the last temptation, "to do the right thing for the wrong reason," is the greatest treason.

25. Compare Martin Luther King's accusation that the Birmingham, Alabama, police used "the moral means of nonviolence to maintain the immoral end of racial injustice" as a different example of taking the moral high road in doing the right thing for the wrong reason. See King's Letter from Birmingham Jail, reprinted in Joel Feinberg and Hyman Gross, Philosophy of Law, Wadsworth, $5^{\text {th }}$ edition, 1995 , p. 120.

26 See Joel Feinberg, "Limits to the free expression of opinion," (Philosophy of Law, Feinberg and Gross, eds., Wadsworth, 1995, fifth edition, pp. 255 256).

27 Ibid. Feinberg points out that only in the most egregious cases has criminal liability been imposed for defamation, but that there are civil remedies for harm caused to one's reputation by having been defamed. Presumably, the same sort of legal remedies might be extended to victims in malicious truth cases.

28 Doing the wrong thing for the right reason is also possible, as cases of legal entrapment illustrate. Though in many cases of entrapment police manipulate persons' wrongful desires in order to incite criminal conduct (by, e.g., leaving an unattended suitcase in a bus station), they sometimes take advantage of such morally laudatory traits as kindness and friendliness, causing persons to act wrongly (i.e. illegally) for right (i.e. morally commendable) reasons. Though legal philosophers frequently view entrapment as a kind of excusable 


\section{PAUL M. HUGHES}

temptation, there is a puzzle about this if one believes, with George Fletcher, that succumbing to temptation is "a paradigm case of blameworthy behavior." See Fletcher, Rethinking Criminal Law, (Little Brown, 1978), p.542. See also J.D. Heydon, "The Problems of Entrapment," Cambridge Law Journal 32.2, November, 1973, pp.268-286.

29 The moral status of deliberate intrapersonal (i.e. entirely self-referential) temptation is perhaps partly illuminated by the same sort of Kantian analysis I have applied to interpersonal temptation. Indeed, deliberately stimulating one's own wrongful desires seems to be a clear case of using a person (oneself) as a means to an end, but here the analysis gets murky, for what is the "end" for which one uses oneself when one deliberately tempts oneself? We may, of course, be weak, and deliberately tempt ourselves knowing we will yield to the temptation and experience the pleasure (and other feelings) of wrongdoing. In such cases we use ourselves as a means to evil. But intentionally subjecting oneself to temptation may have a nobler purpose, such as seeking greater moral self-knowledge by "testing" one's virtues. Surely this is not necessarily wrong. Perhaps a Kantian analysis of the morality of temptation would acknowledge the moral permissibility of selftempting for purposes of promoting moral autonomy. In this way selftempting may be compatible with treating oneself as an end (with dignity and respect) while simultaneously using oneself as a means.

30 Provided that the utterance is not an instance of non-moral temptation like those discussed at the start of this paper. If it is non-moral, then its meaning is clear by itself.

31 Unless a tempter should know of certain effects he has on others, in which case his unintentional stimulation of another person's wrongful desires may be blameworthy.

32 We should bear in mind that a person may be blamelessly morally despicable. A person who routinely causes undeserved harm to others from a habitual exercise of vices which dominate her character may not be responsible (i.e. morally blameworthy) either for possessing the vices or for the harm caused by them. It does not follow from this, however, that such a person is not morally censurable. 